\title{
Efficient Cp*Ir Catalysts with Imidazoline Ligands for $\mathrm{CO}_{2}$ Hydrogenation
}

\author{
Shaoan Xu, ${ }^{[a, b]}$ Naoya Onishi, ${ }^{*[a, b]}$ Akihiro Tsurusaki, ${ }^{[a]}$ Yuichi Manaka, ${ }^{[a]}$ Wan-Hui Wang ${ }^{[c]}$ James T. \\ Muckerman, ${ }^{[\mathrm{d}]}$ Etsuko Fujita, ${ }^{[\mathrm{d}]}$ and Yuichiro Himeda* ${ }^{* \mathrm{a}, \mathrm{b}]}$
}

\begin{abstract}
We report newly developed iridium catalysts with electrondonating imidazoline moieties as ligands for $\mathrm{CO}_{2}$ hydrogenation to formate in aqueous solution. Interestingly, these new complexes promote $\mathrm{CO}_{2}$ hydrogenation much more effectively than their imidazole analogues, exhibiting the turnover frequency (TOF) of $1290 \mathrm{~h}^{-1}$ for the bisimidazoline complex compared to that of $20 \mathrm{~h}^{-1}$ for the bisimidazole complex at $1 \mathrm{MPa}$ and $50{ }^{\circ} \mathrm{C}$. In addition, the hydrogenation proceeds smoothly even under atmospheric pressure at room temperature. The TOF of $43 \mathrm{~h}^{-1}$ for the bisimidazoline complex was comparable to that of a dinuclear complex $\left(70 \mathrm{~h}^{-1}\right.$, highest TOF reported) [Nat. Chem. 2012, 4, 383], which incorporated proton-responsive ligands with pendent-OH groups in the second coordination sphere. The catalytic activity of the complex with an $\mathrm{N}$-methylated imidazoline moiety was much the same as the corresponding pyridylimidazoline analogue. This result and the UVvis titrations of the imidazoline complexes indicate that the high activity is not attributable to the deprotonation of $\mathrm{NH}$ on the imidazoline under the reaction conditions.
\end{abstract}

For a future hydrogen-based economy, the development of hydrogen storage and transfer technology is highly desired in terms of energy and cost efficiency as well as safety. One of the promising solutions is conversion of hydrogen gas to a liquid chemical compound. ${ }^{[1]}$ From the late 1970s, the combination of $\mathrm{CO}_{2}$ hydrogenation and dehydrogenation of formic acid (FA) has been regarded as a viable hydrogen storage system. ${ }^{[2]}$ Furthermore, $\mathrm{CO}_{2}$ hydrogenation has attracted attention from the viewpoint of small molecule activation as well as $\mathrm{CO}_{2}$ utilization. ${ }^{[3]}$ A number of transition metal catalysts for $\mathrm{CO}_{2}$ hydrogenation to formate and FA have been reported for $\mathrm{Cp}^{*} \mathrm{Ir}$ complexes (Scheme 1) as well as for complexes of $\mathrm{Fe},{ }^{[4]} \mathrm{Ru}^{[5]}$ $\mathrm{Cu}^{\left[{ }^{[6]}\right.} \mathrm{Co}^{[7]}$ and $\mathrm{Rh}^{[8]}$ The development of Ir catalysts for $\mathrm{CO}_{2}$ hydrogenation has been especially marked in recent years. There is a wide variety of ligand backbones that link to the iridium center: phosphine-type, ${ }^{[9]}$ pincer-type ${ }^{[10]} \mathrm{NHC}$ carbenetype ${ }^{[11]}$ bipyridine-type,${ }^{[12]}$ and so on ${ }^{[13]}$ In addition, the realization of a hydrogen storage system in aqueous solution is

[a] Dr. S.Xu, Dr. N.Onishi, Dr. A. Tsurusaki, Dr. Y. Manaka, Dr. Y. Himeda

National Institute of Advanced Industrial Science and Technology Tsukuba Central 5, 1-1-1 Higashi, Tsukuba, Ibaraki, 305-8565, Japan

E-mail: n.onishi@aist.go.jp. himeda.y@aist.go.jp

[b] Dr. S.Xu, Dr. N.Onishi, Dr. Y. Himeda

Japan Science and Technology Agency, ACT-C

4-1-8 Honcho, Kawaguchi, Saitama, 332-0012 Japan

[c] Dr. W-H. Wang

School of Petroleum and Chemical Engineering, Dalian University of Technology

Panjin 124221, China

[d] Dr. E. Fujita, Dr. J. T. Muckerman

Chemistry Department, Brookhaven National Laboratory

Upton, NY 11973-5000, United States

Supporting information for this article is given via a link at the end of the document. desirable from the viewpoint of green chemistry.

Recently, a series of water-soluble $\mathrm{Cp}^{*} \operatorname{Ir}\left(\mathrm{N}^{\wedge} \mathrm{N}\right)$ complexes has been found to have good catalytic efficiency for $\mathrm{CO}_{2}$ hydrogenation. ${ }^{[12 c, 14]}$ Our previous reports demonstrated that the introduction of electron-donating ligands toward the Ir center improved the catalytic activity for hydrogenation of $\mathrm{CO}_{2}$ and dehydrogenation of FA. In particular, an acidic hydroxy moiety on a ligand, which provides an electron-donating oxyanion by deprotonation under basic conditions (a so called "protonresponsive" ligand), dramatically accelerated catalytic $\mathrm{CO}_{2}$ hydrogenation. ${ }^{[12 \mathrm{c}, 14 \mathrm{a}]}$ On the other hand, the introduction of a ligand with a five-membered ring, i.e., azole, significantly improved the catalytic efficiency in comparison with a complex with an unsubstituted bipyridine reference ligand, $\left[\mathrm{Cp} * \operatorname{Ir}(\mathrm{Bpy})\left(\mathrm{H}_{2} \mathrm{O}\right)\right] \mathrm{SO}_{4}$, which was attributed to the strong electron donation of the azole moiety. ${ }^{[14 c, 15]}$ Very recently, we developed an Ir complex having a pyrimidyl-imidazoline moiety that showed extremely high catalytic activity (TOF up to 322,000 $\mathrm{h}^{-1}$ ) compared to its imidazole analogues for dehydrogenation of FA. ${ }^{[16]}$ In addition, Xiao et al. reported that the phenylimidazoline analogue effectively catalyzed dehydrogenation of FA using $\mathrm{NEt}_{3}{ }^{\left[{ }^{17]}\right.}$ Similar to the hydrogenation of $\mathrm{CO}_{2}$, the catalytic efficiency of FA dehydrogenation with $\mathrm{Cp}^{*} \mathrm{Ir}$ complexes was thought to be improved by an increase in electron donation by the ligand. ${ }^{[18]}$ These results led to the hypothesis that the imidazoline moiety would be the proper ligand backbone for $\mathrm{CO}_{2}$ hydrogenation. Herein, we report the efficient hydrogenation of $\mathrm{CO}_{2}$ using simple imidazoline complexes in basic water.

As shown in Scheme 1, we synthesized the new iridium complexes 6-8 with imidazoline derivatives (see Detailed Procedure in Supporting Information and Figures S1 and S2 for calculated DFT geometries of the six- and five-coordinate complexes of 7). The results of complexes 6-8 for catalytic $\mathrm{CO}_{2}$ hydrogenation (conditions: [cat] $=0.02 \mathrm{mM},\left[\mathrm{KHCO}_{3}\right]=2.0 \mathrm{M}, 50$ ${ }^{\circ} \mathrm{C}, 1 \mathrm{MPa}$ of $\mathrm{H}_{2} / \mathrm{CO}_{2}(1 / 1), 1 \mathrm{hr}$ ) are shown in Table 1 along with those of the previously reported complexes, 1-5 (see Scheme 1) for comparison. These complexes were able to catalyze hydrogenation in aqueous solution without any organic additives. Complex 6 showed good catalytic activity (entry 6), which is better than conventional complexes such as 1, 4 and $\mathbf{5}$. Since the introduction of one imidazoline moiety in a ligand increased the catalytic activity, we also examined complex 7 having two imidazoline moieties. The TOF of $1290 \mathrm{~h}^{-1}$ of 7 was much higher than that of complex $\mathbf{2}$ with the proton-responsive ligand with $\mathrm{OH}$ groups $\left(p K_{a}=5.2\right) \cdot{ }^{[12 b]}$ To the best of our knowledge, this is the first report that a ligand such as an imidazoline without a protonresponsive $\mathrm{OH}$ group was more effective for $\mathrm{CO}_{2}$ hydrogenation in aqueous solution than the proton-responsive ligand 4DHBP. This is attributable to the powerful electron-donation of an imidazoline moiety. In addition, the complex 7 showed slightly lower catalytic activity than $\mathbf{3}$ which also has two protonresponsive $\mathrm{OH}$ groups, but the synthesis of the ligand 4 was easier because of commercially available precursors. In other words, complex 7 was simple yet effective. Although the TOF 


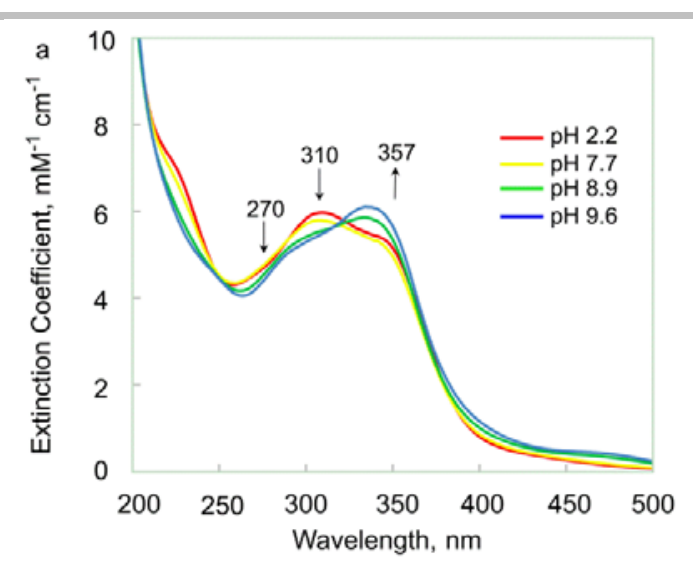

b

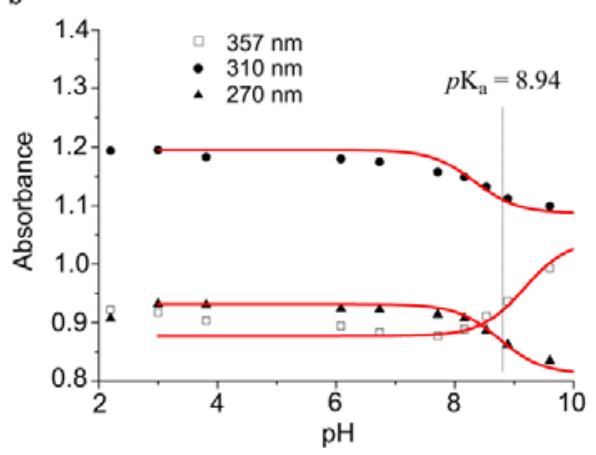

Figure 2. (a) UV-Vis absorption spectra of complex $7(0.2 \mathrm{mM})$ in a pH titration and (b) absorbance change at a single wavelength as a function of $\mathrm{pH}$ Boltzmann fits are depicted by the red lines.

The reason that an imidazoline ligand is effective in promoting the hydrogenation of $\mathrm{CO}_{2}$ is attributable to the influence of the amidine backbone in the imidazoline moiety. The imine substituent in the amidine structure has a resonance structure in which it is partially converted to an amide form. The electron density of the Ir center is increased by ligation of the amide that is more electron rich than the imine. However, in aromatic imidazole, which has an amidine backbone the same as an imidazoline, its $\pi$-electrons are delocalized over the entire ligand. By contrast, $\pi$-electrons on non-aromatic imidazoline are delocalized within the amidine moieties, leading to an increase in the electron density of the $\mathrm{N}$ atom coordinating the Ir center in comparison with imidazole. As described in the Introduction, the catalytic efficiency of $\mathrm{CO}_{2}$ hydrogenation is improved by an increase in electron donation from the ligand to the Ir center. Hence, the bisimidazoline complex 7 is an outstanding complex for $\mathrm{CO}_{2}$ hydrogenation.

Comparing the electronic ligand effects of the 4- or 6hydroxy group in a pyridinol moiety with those of an imidazoline moiety, in the former there is a moderate $\sigma$ donation effect at low $\mathrm{pH}$, but at the higher $\mathrm{pH}$ at which deprotonation of the hydroxy group occurs the resulting oxyanion has a keto resonance structure that is a strong $\pi$-donor. This effect is enhanced by the strong $\pi$-acceptor property of the metal center in the $\mathrm{Cp}^{*} \operatorname{Ir}(\mathrm{III})$ moiety. This causes the weakening or detachment of the aqua ligand, creating a site for $\mathrm{H}_{2}$ heterolysis, the rate-determining step in $\mathrm{CO}_{2}$ hydrogenation. In the case of the imidazoline moiety, the restricted conjugation of the double bonds is extended by a resonance structure that places negative charge on the $\pi$ accepting $\operatorname{Ir}(\mathrm{III})$ center through $\pi$-donation even at low $\mathrm{pH}$.

In conclusion, we have reported that imidazoline ligands improve the Ir-catalyzed hydrogenation of $\mathrm{CO}_{2}$ to formate. In particular, the bisimidazoline complex 7 achieved a high TOF value under both pressurized and ambient conditions. There are many $\mathrm{N}^{\wedge} \mathrm{N}$-bidentate ligands that have been linked to $\mathrm{Cp}^{*} \mathrm{Ir}$ complexes for $\mathrm{CO}_{2}$ hydrogenation, but a ligand such as bisimidazoline that is not completely conjugated has not previously been reported as an effective ligand for catalytic $\mathrm{CO}_{2}$ hydrogenation. This is a potentially important finding for expanding the "toolbox" for the design of improved complexes for $\mathrm{CO}_{2}$ hydrogenation.

\section{Acknowledgements}

S. X., N. O., Y. M., and Y. H. thank the Japan Science and Technology Agency (JST), ACT-C for financial support. W.-H. W. thanks the financial support from Dalian University of Technology (the Fundamental Research Funds for the Central Universities, Grant No. DUT14RC(3)082; Grant No. 844401) and National Natural Science Foundation of China (Grant No. 21402019). The work at BNL was carried out under contract DESC00112704 with the U.S. Department of Energy, Office of Science, Office of Basic Energy Sciences.

Keywords: Homogeneous Catalysis • Ir Complex $\bullet \mathrm{CO}_{2}$ Hydrogenation

[1] a) W.-H. Wang, Y. Himeda, J. T. Muckerman, G. F. Manbeck, E. Fujita, Chem. Rev. 2015, DOI 10.1021/acs.chemrev.1025b00197; b) Q.-L. Zhu, Q. Xu, Energy Environ. Sci. 2015, 8, 478-512.

[2] R. Williams, R. S. Crandall, A. Bloom, Appl. Phys. Lett. 1978, 33, 381383.

[3] E. Fujita, A. S. Goldman, Inorg. Chem. 2015, 54, 5040-5042.

[4] a) C. Ziebart, C. Federsel, P. Anbarasan, R. Jackstell, W. Baumann, A. Spannenberg, M. Beller, J. Am. Chem. Soc. 2012, 134, 20701-20704; b) F. Bertini, I. Mellone, A. lenco, M. Peruzzini, L. Gonsalvi, ACS Catal. 2015, 5, 1254-1265; c) O. Rivada-Wheelaghan, A. Dauth, G. Leitus, Y. Diskin-Posner, D. Milstein, Inorg. Chem. 2015, 54, 4526-4538; d) Y. Zhang, A. D. Maclntosh, J. L. Wong, E. A. Bielinski, P. G. Williard, B. Q. Mercado, N. Hazari, W. H. Bernskoetter, Chem. Sci. 2015, 6, 42914299; e) F. Zhu, L. Zhu-Ge, G. Yang, S. Zhou, ChemSusChem 2015, 8, 609-612; f) H. Fong, J. C. Peters, Inorg. Chem. 2015, 54, 5124-5135.

[5] a) P. G. Jessop, T. Ikariya, R. Noyori, Nature 1994, 368, 231-233; b) G. Papp, J. Csorba, G. Laurenczy, F. Joó, Angew. Chem.-Int. Edit. 2011, 50, 10433-10435; c) K. Muller, Y. Sun, W. R. Thiel, ChemCatChem 2013, 5, 1340-1343; d) G. A. Filonenko, R. van Putten, E. N. Schulpen, E. J. M. Hensen, E. A. Pidko, ChemCatChem 2014, 6, 1526-1530; e) S. Moret, P. J. Dyson, G. Laurenczy, Nat. Commun. 2014, 5, 4017; f) J. Kothandaraman, M. Czaun, A. Goeppert, R. Haiges, J.-P. Jones, R. B. May, G. K. S. Prakash, G. A. Olah, ChemSusChem 2015, 8, $1442-$ 1451; g) C. A. Huff, M. S. Sanford, ACS Catal. 2013, 3, 2412-2416.

[6] R. Watari, Y. Kayaki, S.-i. Hirano, N. Matsumoto, T. Ikariya, Adv. Synth. Catal. 2015, 357, 1369-1373.

[7] a) Y. M. Badiei, W.-H. Wang, J. F. Hull, D. J. Szalda, J. T. Muckerman, Y. Himeda, E. Fujita, Inorg. Chem. 2013, 52, 12576-12586; b) M. S. Jeletic, M. L. Helm, E. B. Hulley, M. T. Mock, A. M. Appel, J. C. Linehan, ACS Catal. 2014, 4, 3755-3762. 
COMMUNICATION

Novel complex having imidazoline ligand showed much higher catalytic activity than that conventional one having imidazole ligand for the $\mathrm{CO}_{2}$ hydrogenation. Only change from double bond in imidazole to single bond in imidazoline increased catalytic activity in 60 times.

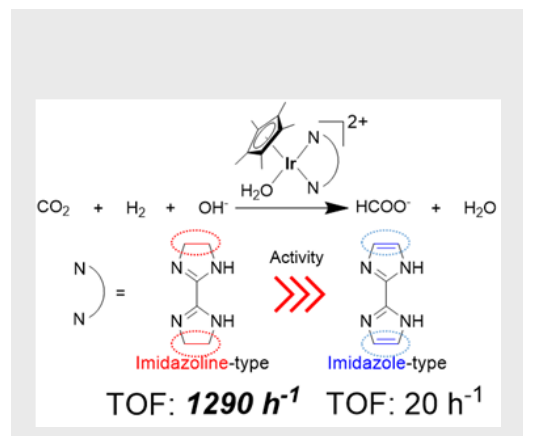

Shaoan Xu, Naoya Onishi, * Akihiro Tsurusaki, Yuichi Manaka, Wan-Hui Wang, James T. Muckerman, Etsuko Fujita, and Yuichiro Himeda*

Page No. - Page No.

Efficient Cp*Ir Complexes with Imidazoline Ligands for $\mathrm{CO}_{2}$

Hydrogenation 


\section{Efficient Cp*Ir Catalysts with Imidazoline Ligands for $\mathrm{CO}_{2}$ Hydrogenation}

Shaoan $\mathrm{Xu},{ }^{[a, b]}$ Naoya Onishi, ${ }^{[a, b]}$ Akihiro Tsurusaki, ${ }^{[a]}$ Yuichi Manaka, ${ }^{[a]}$ Wan-Hui Wang, ${ }^{[c]}$ James T. Muckerman, ${ }^{[\mathrm{d}]}$ Etsuko Fujita, ${ }^{[\mathrm{d}]}$ and Yuichiro Himeda ${ }^{\star[a, b]}$

\section{Supporting Information}

\begin{tabular}{l}
\hline [a] National Institute of Advanced Industrial Science and Technology Tsukuba Central 5, 1-1-1 Higashi, Tsukuba, Ibaraki, 305-8565, \\
Japan \\
E-mail: n.onishi@aist.go.jp. himeda.y@aist.go.jp \\
Jb] Japan Science and Technology Agency, ACT-C \\
4-1-8 Honcho, Kawaguchi, Saitama, 332-0012 Japan \\
[c] School of Petroleum and Chemical Engineering, Dalian University of Technology \\
Panjin 124221, China \\
[d] Chemistry Department, Brookhaven National Laboratory \\
Upton, NY 11973-5000, United States
\end{tabular} 


\section{Experimental section}

General. Unless otherwise noted, materials were purchased from commercial suppliers and used without further purification. All manipulations were carried out under an argon atmosphere using standard Schlenk techniques or in a glovebox, and all aqueous solutions were degassed prior to use. ${ }^{1} \mathrm{H}$ NMR and ${ }^{13} \mathrm{C}$ NMR spectra were recorded on Bruker Avance 400 and 500 spectrometers using tetramethylsilane or sodium 3-(trimethylsilyl)-1-propanesulfonate as an internal standard. Elemental analyses were performed by a CE Instruments EA1110 elemental analyzer. $\mathrm{pH}$ values were measured on an Orion 3-Star $\mathrm{pH}$ meter with a glass electrode after calibration with standard buffer solutions. ESI-MS data were collected on a Shimadzu LCMS-2020. Formate concentrations were monitored by an HPLC on an anion-exclusion column (Tosoh TSKgel $\mathrm{SCX}\left(\mathrm{H}^{+}\right)$) using an aqueous $\mathrm{H}_{3} \mathrm{PO}_{4}$ solution $(20 \mathrm{mM})$ as an eluent and a UV detector $(\lambda=210 \mathrm{~nm})$. Water used in the reactions was obtained from a Simplicity water purification system. 2,2'-Bisimidazoline was purchased (Molport) and used without further purification. $\left[\mathrm{Cp} * \operatorname{Ir}\left(\mathrm{OH}_{2}\right)_{3}\right]\left[\mathrm{SO}_{4}\right]$ was synthesized according to a previous report. ${ }^{1}$

General procedure for catalytic hydrogenation of $\mathbf{C O}_{2}: \mathrm{A} \mathrm{KHCO}_{3}$ aqueous solution $(2.0 \mathrm{M}$, $\mathrm{pH} 8.3,10 \mathrm{~mL})$ with complexes $\left(2 \times 10^{-4} \mathrm{mmol}\right)$ was degassed by three cycles of Freeze-Pump-Thaw in a flask, and was transferred into a stainless autoclave. After $10 \mathrm{~min}$. stabilization at $50{ }^{\circ} \mathrm{C}$ under $1.0 \mathrm{MPa}$ of $\mathrm{H}_{2} / \mathrm{CO}_{2}(1 / 1)$ gas, the reaction was started by stirring $(1500 \mathrm{rpm})$. The stirring was stopped after $1 \mathrm{~h}$ and the pressurized gas was released to measure the concentration of formate in the resulting solution by HPLC.

Hydrogenation of $\mathbf{C O}_{2}$ under ambient conditions: $\mathrm{A} \mathrm{NaHCO}_{3}$ aqueous solution $(20 \mathrm{~mL})$ with a complex (see Table S2) was degassed by three cycles of Freeze-Pump-Thaw in a flask. The solution was vigorously stirred at atmospheric pressure $\left(0.1 \mathrm{MPa}\right.$ of $\left.\mathrm{H}_{2} / \mathrm{CO}_{2}(1: 1)\right)$ and temperature $\left(25^{\circ} \mathrm{C}\right)$. At appropriate intervals, samples were removed and analyzed by HPLC. 


\section{Synthesis of ligands.}

Synthesis of ligands $\mathbf{L 6}$ and $\mathbf{L 8}$ for complexes $\mathbf{6}$ and 8: The ligands were synthesized according to the reported processes. ${ }^{2}$

1.1. Synthesis of 4,5-dihydro-2-(pyridin-2-yl)-1H-imidazole (L6).<smiles>c1ccc(C2=NCCN2)nc1</smiles>

tert-Butyl isocyanide ( $170 \mu \mathrm{L}, 1.5 \mathrm{mmol}$ ) was added to a mixture of cesium carbonate (423 $\mathrm{mg}$, $1.3 \mathrm{mmol})$, anhydrous toluene $(5 \mathrm{~mL}), 2$-bromopyridine $(158 \mathrm{mg}, 1.0 \mathrm{mmol})$, ethylenediamine (334 $\mu \mathrm{L}, 5 \mathrm{mmol}$ ), palladium(II) chloride ( $8.9 \mathrm{mg}, 0.05 \mathrm{mmol})$, and dppp (41.2 $\mathrm{mg}, 0.1 \mathrm{mmol}$ ). The reaction mixture was stirred at $120{ }^{\circ} \mathrm{C}$ under $\mathrm{N}_{2}$ atmosphere for $24 \mathrm{~h}$. After cooling to room temperature, the mixture was filtered through celite and washed with water $(5 \mathrm{~mL} \times 2)$. The filtrate was extracted by dichloromethane (DCM, $10 \mathrm{~mL} \times 3$ ). The combined organic phase was washed with brine $(10 \mathrm{~mL} \times 3)$, dried over anhydrous $\mathrm{Na}_{2} \mathrm{SO}_{4}$, and concentrated to give the crude product as a black solid. It was then purified by column chromatography on silica gel using DCM/MeOH $(10: 1)$ as eluent to give the product $(0.14 \mathrm{~g}, 0.95 \mathrm{mmol}$, yield: $95 \%)$ as a yellow solid. ${ }^{1} \mathrm{H}$ NMR $\left(\mathrm{CDCl}_{3}, 400 \mathrm{MHz}\right): \delta 8.57$ (d, $\left.J=4.8 \mathrm{~Hz}, 1 \mathrm{H}\right), 8.19$ (t, $\left.J=7.6 \mathrm{~Hz}, 1 \mathrm{H}\right), 7.78$ (td, $J=7.6,1.6 \mathrm{~Hz}$, $1 \mathrm{H}), 7.36(\mathrm{dd}, J=7.6,4.8 \mathrm{~Hz}, 1 \mathrm{H}), 3.86(\mathrm{~s}, 4 \mathrm{H}) .{ }^{13} \mathrm{C} \mathrm{NMR}\left(\mathrm{CDCl}_{3}, 100 \mathrm{MHz}\right): \delta 164.30,148.58$, $148.51,136.60,125.07,122.30,50.51$.

1.2 Synthesis of 4,5-dihydro-2-(pyridin-2-yl)-1-methyl-imidazole (L8).

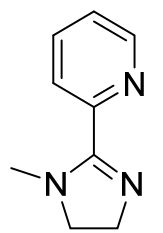

The title compound was synthesized by using $N$-methylethylenediamine as diamine according to the method described in procedure 1.1. The crude product was purified by column chromatography on silica gel using dichloromethane/methanol (10:1) as eluent to give the product (yield: $80 \%$ ) as a yellow oil. ${ }^{1} \mathrm{H}$ NMR $\left(\mathrm{CDCl}_{3}, 400 \mathrm{MHz}\right): \delta 8.63(\mathrm{~d}, J=4.8 \mathrm{~Hz}, 1 \mathrm{H}), 7.85(\mathrm{~d}, J=$ $7.6 \mathrm{~Hz}, 1 \mathrm{H}), 7.75$ (td, $J=7.6,1.6 \mathrm{~Hz}, 1 \mathrm{H}), 7.34-7.27$ (m, 1H), 3.89 (t, $J=10.0 \mathrm{~Hz}, 2 \mathrm{H}), 3.50(\mathrm{t}, J$ $=10.0 \mathrm{~Hz}, 2 \mathrm{H}), 3.04(\mathrm{~s}, 3 \mathrm{H}) .{ }^{13} \mathrm{C} \mathrm{NMR}\left(\mathrm{CDCl}_{3}, 100 \mathrm{MHz}\right): \delta 165.62,150.59,148.44,136.48$, $124.22,124.03,54.31,53.00,35.59$. 


\section{Synthesis of complexes.}

2.1 Synthesis of complex $\left[\mathrm{Cp} * \operatorname{Ir}(\mathbf{L 6})\left(\mathrm{OH}_{2}\right)\right] \mathrm{SO}_{4}(\mathbf{6})$.

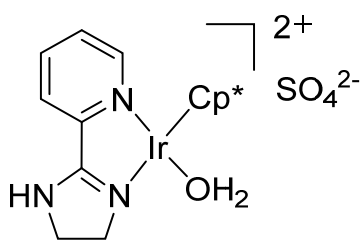

A mixture of $\left[\mathrm{Cp} * \operatorname{Ir}\left(\mathrm{OH}_{2}\right)_{3}\right] \mathrm{SO}_{4}(143.7 \mathrm{mg}, 0.3 \mathrm{mmol})$ and $\mathbf{L 6}(44.2 \mathrm{mg}, 0.3 \mathrm{mmol})$ in $15 \mathrm{~mL} \mathrm{H} \mathrm{H}_{2} \mathrm{O}$ was stirred at room temperature under Ar atmosphere for $18 \mathrm{~h}$. The solution was filtered to remove the insoluble solid. The filtrate was concentrated and dried at $50{ }^{\circ} \mathrm{C}$ under vacuum for $5 \mathrm{~h}$ to give the product as a yellow solid (158 $\mathrm{mg}, 90 \%$ ). Purification was carried out by reprecipitation using $\mathrm{MeOH} / \mathrm{Et}_{2} \mathrm{O}(1 / 1) .{ }^{1} \mathrm{H} \mathrm{NMR}\left(\mathrm{D}_{2} \mathrm{O}, 400 \mathrm{MHz}\right): \delta 8.98(\mathrm{~d}, J=5.2 \mathrm{~Hz}, 1 \mathrm{H}), 8.18(\mathrm{t}, J=8.0 \mathrm{~Hz}, 1 \mathrm{H})$, $7.97(\mathrm{~d}, J=8.0 \mathrm{~Hz}, 1 \mathrm{H}), 7.81-7.74(\mathrm{~m}, 1 \mathrm{H}), 4.18(\mathrm{t}, J=10.8 \mathrm{~Hz}, 2 \mathrm{H}), 3.97(\mathrm{t}, J=10.8 \mathrm{~Hz}, 2 \mathrm{H})$, 1.61 (s, $15 \mathrm{H}) .{ }^{13} \mathrm{C}\left\{{ }^{1} \mathrm{H}\right\}$ NMR $\left(\mathrm{D}_{2} \mathrm{O}, 100 \mathrm{MHz}\right): \delta 171.37,152.35,146.51,141.49,130.37,125.33$, 87.91, 52.12, 46.03, 8.13. ESI-MS(+): $m / z 474\left[\mathrm{M}-\mathrm{H}_{2} \mathrm{O}-\mathrm{SO}_{4}{ }^{2-}\right]^{+}$. Anal. Calc. for $\mathrm{C}_{18} \mathrm{H}_{24} \mathrm{IrN}_{3} \mathrm{O}_{6} \mathrm{~S}$ + 0.5MeOH: C 36.74, H 4.67, N 6.95. Found: C 36.59, H 4.53, N 6.58.

2.2 Synthesis of bisimidazoline complex $\left[\mathrm{Cp} * \operatorname{Ir}(\mathbf{L} 7)\left(\mathrm{OH}_{2}\right)\right] \mathrm{SO}_{4}(\mathbf{7})$.

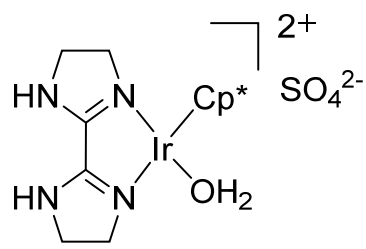

Complex 7 was synthesized by using $2,2^{\prime}$-bisimidazoline as diamine according to the method described in procedure 2.1. ${ }^{1} \mathrm{H}$ NMR $\left(\mathrm{D}_{2} \mathrm{O}, 400 \mathrm{MHz}\right): \delta 4.16(\mathrm{t}, J=6.8 \mathrm{~Hz}, 4 \mathrm{H}), 4.00(\mathrm{t}, J=6.8$ $\mathrm{Hz}, 4 \mathrm{H}), 1.75$ (s, 15H). ${ }^{13} \mathrm{C}\left\{{ }^{1} \mathrm{H}\right\} \mathrm{NMR}\left(\mathrm{D}_{2} \mathrm{O}, 100 \mathrm{MHz}\right): \delta 162.89,87.55,52.29,47.39,9.13$. ESI-MS(+): $\mathrm{m} / \mathrm{z} 465\left[\mathrm{M}-\mathrm{H}_{2} \mathrm{O}-\mathrm{SO}_{4}{ }^{2-}-\mathrm{H}\right]^{+}$. Anal. Calc. for $\mathrm{C}_{16} \mathrm{H}_{27} \mathrm{IrN}_{4} \mathrm{O}_{5} \mathrm{~S}+1.5 \mathrm{H}_{2} \mathrm{O}: \mathrm{C} 31.67, \mathrm{H}$ 4.98, N 9.23. Found: C 32.06, H 4.84, N 8.94.

Caution: This compound should be stored under inert gas atmosphere because its color changed from orange to green in the air. This implies that the complex was gradually decomposed by oxygen.

2.3 Synthesis of complex $\left[\mathrm{Cp} * \operatorname{Ir}(\mathbf{L 8})\left(\mathrm{OH}_{2}\right)\right] \mathrm{SO}_{4}(\mathbf{8})$.

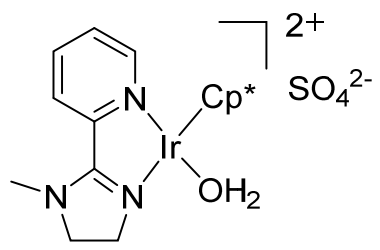


Complex $\mathbf{8}$ was synthesized using $\mathbf{L 8}$ as ligand according to the method described in procedure 2.1. ${ }^{1} \mathrm{H}$ NMR ( $\left.\mathrm{D}_{2} \mathrm{O}, 400 \mathrm{MHz}\right): \delta 9.12(\mathrm{~d}, J=5.6 \mathrm{~Hz}, 1 \mathrm{H}), 8.36(\mathrm{~d}, J=8.0 \mathrm{~Hz}, 1 \mathrm{H}), 8.29(\mathrm{t}, J=$ $8.0 \mathrm{~Hz}, 1 \mathrm{H}), 7.90-7.86(\mathrm{~m}, 1 \mathrm{H}), 4.12-4.08(\mathrm{~m}, 4 \mathrm{H}), 3.44(\mathrm{~s}, 3 \mathrm{H}), 1.70(\mathrm{~s}, 15 \mathrm{H}) .{ }^{13} \mathrm{C}\left\{{ }^{1} \mathrm{H}\right\} \mathrm{NMR}$ $\left(\mathrm{D}_{2} \mathrm{O}, 100 \mathrm{MHz}\right): \delta 169.12,153.59,146.88,141.63,130.59,126.86,88.31,55.88,50.54,34.85$, 8.44. ESI-MS(+): $\mathrm{m} / \mathrm{z} 486\left[\mathrm{M}-\mathrm{H}_{2} \mathrm{O}-\mathrm{SO}_{4}{ }^{2-}-3 \mathrm{H}\right]^{+}$. Anal. Calc. for $\mathrm{C}_{19} \mathrm{H}_{28} \mathrm{IrN}_{3} \mathrm{O}_{5} \mathrm{~S}+2.5 \mathrm{H}_{2} \mathrm{O}: \mathrm{C}$ 35.23, H 5.14, N 6.49. Found: C 35.54, H 5.13, N 6.15. 
Table S1. $\mathrm{CO}_{2}$ Hydrogenation using complexes 6-8 ${ }^{a}$

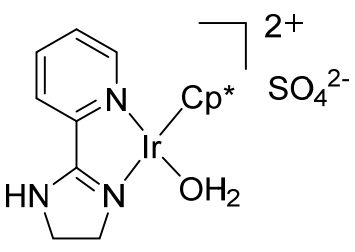

6

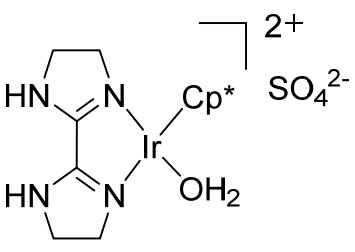

7

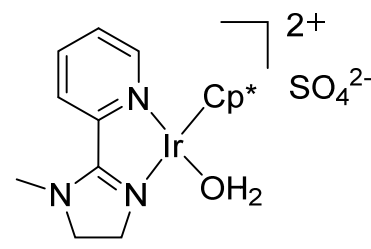

8

\begin{tabular}{|c|c|c|c|c|c|c|c|}
\hline Entry & Cat. & Temp $\left({ }^{\circ} \mathrm{C}\right)$ & Time (h) & TOF $\left(h^{-1}\right)$ & ${ }^{1 s t} \mathrm{TON}$ & ${ }^{2 n d}$ TON & $\begin{array}{c}\text { Average } \\
\text { TON }\end{array}$ \\
\hline 1 & 6 & 50 & 1 & 168 & 170 & 166 & 168 \\
\hline 2 & 6 & 50 & 2 & 149 & 316 & 280 & 298 \\
\hline 3 & 6 & 50 & 4 & 131 & 550 & 505 & 525 \\
\hline 4 & 6 & 50 & 24 & 81 & 2000 & 1870 & 1940 \\
\hline 5 & 6 & 80 & 1 & 400 & 395 & 405 & 400 \\
\hline 6 & 6 & 100 & 1 & 593 & 600 & 585 & 593 \\
\hline 8 & 7 & 50 & 1 & 1290 & 1290 & 1280 & 1290 \\
\hline 9 & 7 & 50 & 2 & 920 & 1900 & 1770 & 1840 \\
\hline 10 & 7 & 50 & 4 & 728 & 2910 & 2900 & 2910 \\
\hline $11^{b}$ & 7 & 50 & 4 & 450 & 1800 & - & - \\
\hline 12 & 7 & 50 & 24 & 168 & 4200 & 3850 & 4030 \\
\hline 13 & 7 & 80 & 1 & 1520 & 1520 & 1520 & 1520 \\
\hline 14 & 7 & 100 & 1 & 842 & 859 & 825 & 842 \\
\hline 15 & 8 & 50 & 1 & 181 & 175 & 186 & 181 \\
\hline 16 & 8 & 50 & 2 & 155 & 318 & 302 & 310 \\
\hline 17 & 8 & 50 & 4 & 147 & 600 & 574 & 587 \\
\hline 18 & 8 & 50 & 24 & 86 & 2100 & 2030 & 2070 \\
\hline 19 & 8 & 80 & 1 & 464 & 468 & 460 & 464 \\
\hline 20 & 8 & 100 & 1 & 413 & 410 & 415 & 413 \\
\hline
\end{tabular}

${ }^{a}$ Carried out with catalyst $(0.2 \mu \mathrm{mol})$ in $10 \mathrm{~mL}$ of $2.0 \mathrm{M} \mathrm{KHCO}_{3}$ aqueous solution (pH 8.3) under 1.0 $\mathrm{MPa} \mathrm{H}_{2} / \mathrm{CO}_{2}(1 / 1)$ with stirring $(1500 \mathrm{rpm})$. The TOF is calculated as TON/time. TONs and avg TONs are shown with 3 significant digits.

${ }^{b} \mathrm{pH}$ of 10 was adjusted by a small amount of KOH solid. 
Table S2. $\mathrm{CO}_{2}$ Hydrogenation using complexes 6-8 under ambient conditions. ${ }^{\mathrm{a}}$

\begin{tabular}{|c|c|c|c|c|}
\hline Entry & Cat. & Time & TON & TOF $\left(h^{-1}\right)$ \\
\hline 1 & 6 & $30 \mathrm{~min}$ & 3 & 6 \\
\hline 2 & 6 & $1 \mathrm{~h}$ & 4 & 4 \\
\hline 3 & 6 & $2 \mathrm{~h}$ & 6 & 3 \\
\hline 4 & 6 & $4 \mathrm{~h}$ & 11 & 3 \\
\hline 5 & 6 & $1 \mathrm{~d}$ & 44 & 2 \\
\hline 6 & 6 & $2 \mathrm{~d}$ & 76 & 1.6 \\
\hline 7 & 6 & $3 \mathrm{~d}$ & 96 & 1.6 \\
\hline 8 & 7 & $30 \mathrm{~min}$ & 27 & 53 \\
\hline 9 & 7 & $1 \mathrm{~h}$ & 43 & 43 \\
\hline 10 & 7 & $2 \mathrm{~h}$ & 75 & 37 \\
\hline 11 & 7 & $4 \mathrm{~h}$ & 121 & 30 \\
\hline 12 & 7 & $1 \mathrm{~d}$ & 298 & 12 \\
\hline 13 & 7 & $2 d$ & 352 & 7 \\
\hline 14 & 7 & $3 \mathrm{~d}$ & 356 & 5 \\
\hline 15 & 8 & $30 \mathrm{~min}$ & 4 & 8 \\
\hline 16 & 8 & $1 \mathrm{~h}$ & 5 & 5 \\
\hline 17 & 8 & $2 \mathrm{~h}$ & 7 & 4 \\
\hline 18 & 8 & $4 \mathrm{~h}$ & 14 & 4 \\
\hline 19 & 8 & $1 \mathrm{~d}$ & 48 & 2 \\
\hline 20 & 8 & $2 \mathrm{~d}$ & 65 & 1.4 \\
\hline 21 & 8 & $3 d$ & 79 & 1.1 \\
\hline
\end{tabular}

${ }^{a}$ Carried out with catalyst $(1.0 \mu \mathrm{mol}$ for complexes 6 and 8,0.5 $\mu$ mol for complex 7) in $20 \mathrm{~mL}$ of $1.0 \mathrm{M} \mathrm{NaHCO}_{3}$ aqueous solution ( $\mathrm{pH} 8.3$ ) under $0.1 \mathrm{MPa} \mathrm{H}_{2} / \mathrm{CO}_{2}(1 / 1)$. The TOF is calculated as TON/time. 

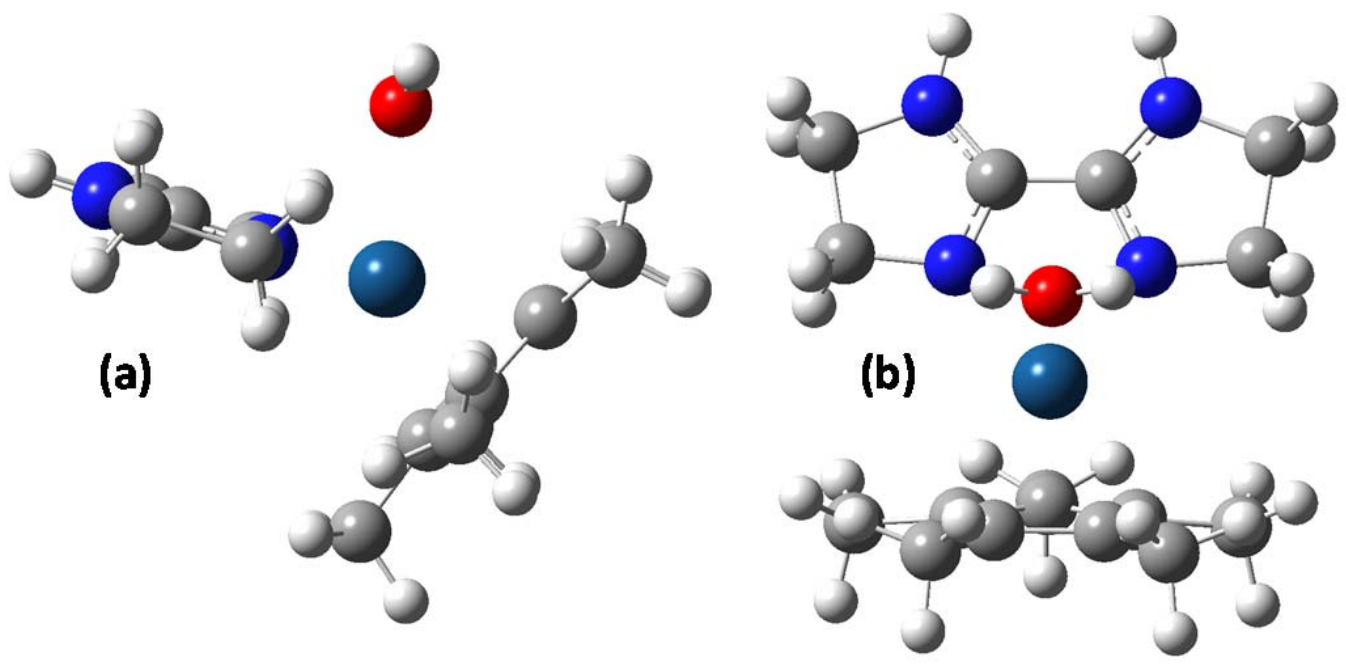

Figure S1. Calculated DFT structure of $\left[\mathrm{Cp} * \operatorname{Ir}(\mathbf{L} 7)\left(\mathrm{OH}_{2}\right)\right]^{2+}$ (7) from two views: (a) from the side, and (b) from the front. [B3LYP functional/LANL2DZ basis/SMD continuum solvation model.]

(a)
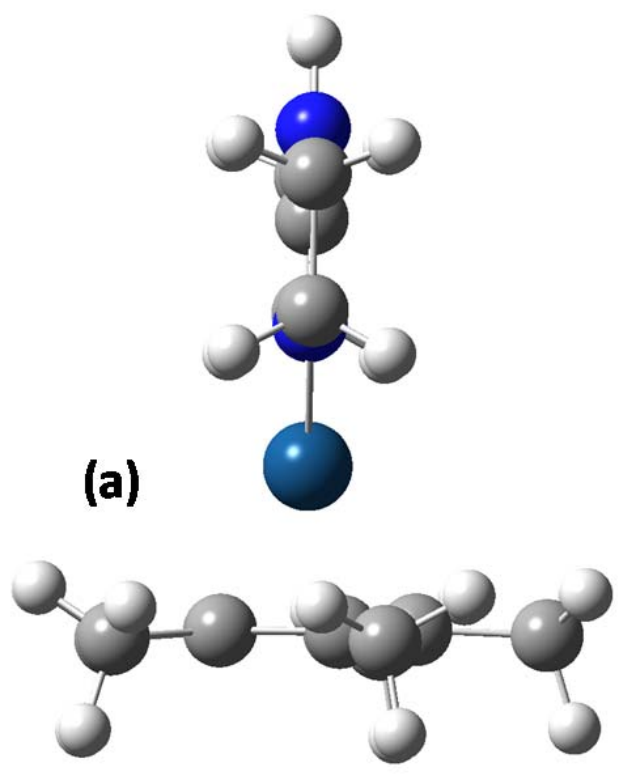

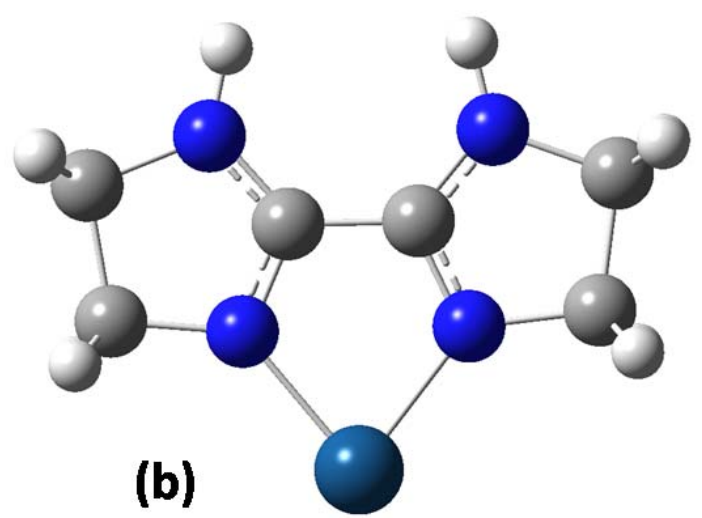

(b)

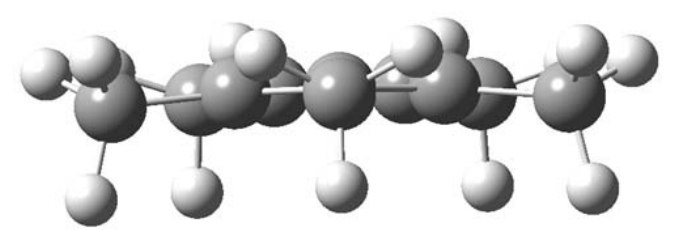

Figure S2. Calculated DFT structure of 5-coordinate $[\mathrm{Cp} * \operatorname{Ir}(\mathbf{L} 7)]^{2+}$ (7) from two views: (a) from the side, and (b) from the front. [B3LYP functional/LANL2DZ basis/SMD continuum solvation model.] 


\section{UV-vis Spectra}

We have measured the UV-vis spectra for all three complexes 6-8 to characterize the deprotonation of the proton-responsive ligands. The result for catalyst $\mathbf{8}$, which doesn't have an acidic proton on the ligand, exhibited a $\mathrm{p} K_{\mathrm{a}}$ of 7.7 (Figure S5). This deprotonation corresponds to the deprotonation of the aqua ligand. The same phenomenon was observed in the result for catalyst 6 (Figure S3). On the other hand, as described in the text, a red shift was observed for catalyst 7 at $\mathrm{pH}$ from 8 to 10 , and the proton on $\mathrm{NH}$ was deprotonated. However, the peak at near $600 \mathrm{~nm}$ suddenly increased by adjusting the $\mathrm{pH}$ up to 11 , implying that $\operatorname{Ir}(\mathrm{III})$ was reduced to $\operatorname{Ir}(\mathrm{I})$ under strong basic conditions. ${ }^{3}$ Although this result means that the deprotonation of the aqua ligand in catalyst 7 was hardly observed, the reaction conditions in the present work corresponded to a $\mathrm{pH}$ of 8.3 .
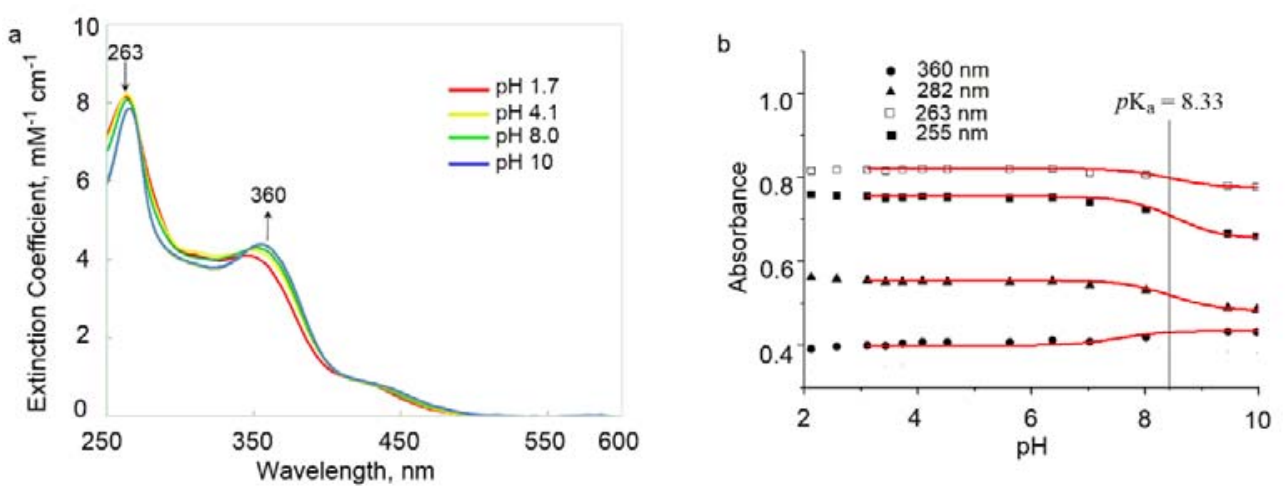

Figure S3. (a) UV-vis absorption spectra of complex $6(0.1 \mathrm{mM})$ in a $\mathrm{pH}$ titration and (b) absorbance change at single wavelength as a function of $\mathrm{pH}$ with Boltzmann fits depicted by red lines.
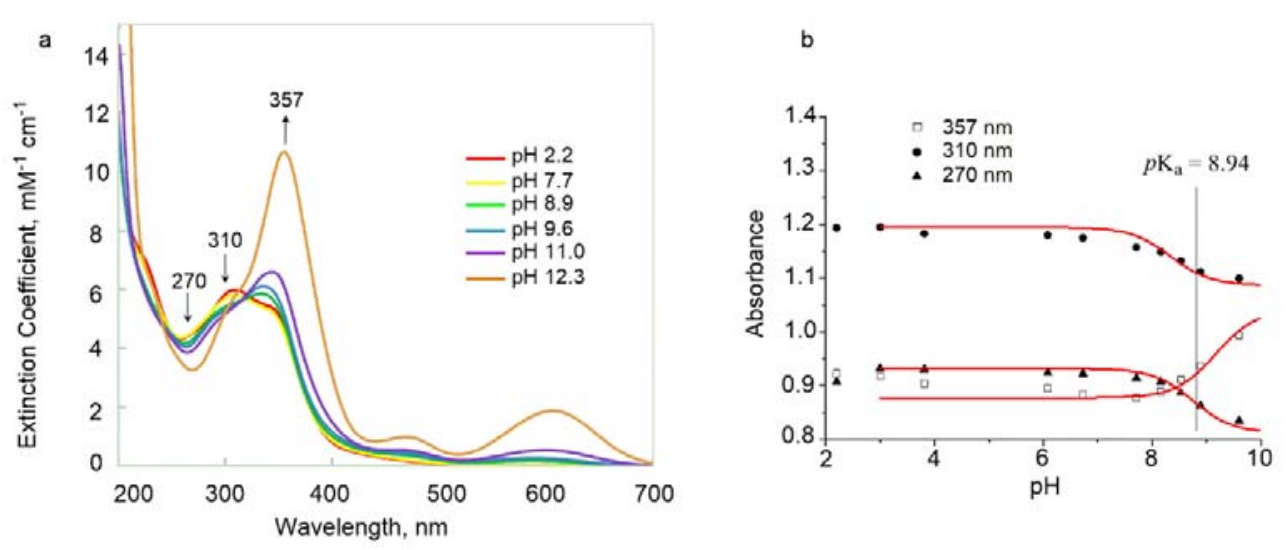

Figure S4. (a) UV-vis absorption spectra of complex $7(0.2 \mathrm{mM})$ in a $\mathrm{pH}$ titration and (b) absorbance change at single wavelength as a function of $\mathrm{pH}$ with Boltzmann fits depicted by red lines. 

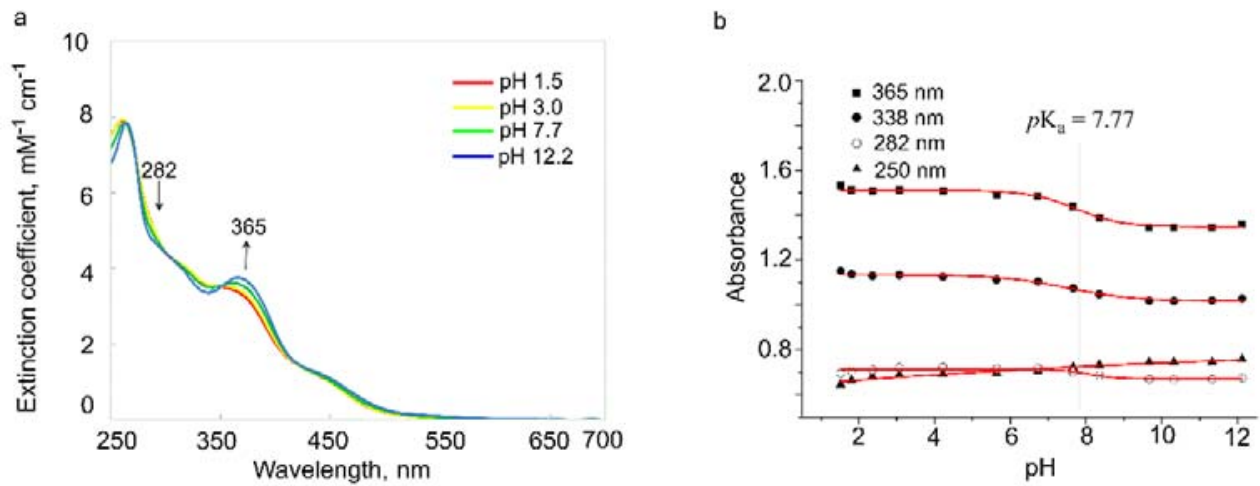

Figure S5. (a) UV-vis absorption spectra of complex $8(0.2 \mathrm{mM})$ in a $\mathrm{pH}$ titration and (b) absorbance change at single wavelength as a function of $\mathrm{pH}$ with Boltzmann fits depicted by red lines.

\section{References}

(1) Ogo, S.; Makihara, N.; Watanabe, Y. Organometallics 1999, 18, 5470-5474.

(2) Geden, J. V.; Pancholi, A. K.; Shipman, M. J. Org. Chem. 2013, 78, 4158-4164.

(3) (a) Manbeck, G. F.; Muckerman, J. T.; Szalda, D. J.; Himeda, Y; Fujita, E. J. Phys. Chem. B, 2015, 119,7457-7466; (b) Suenobu, T.; Guldi, D. M.; Ogo, S.; Fukuzumi, S. Angew. Chem. Int. Ed. 2003, 42, 5492-5495. 


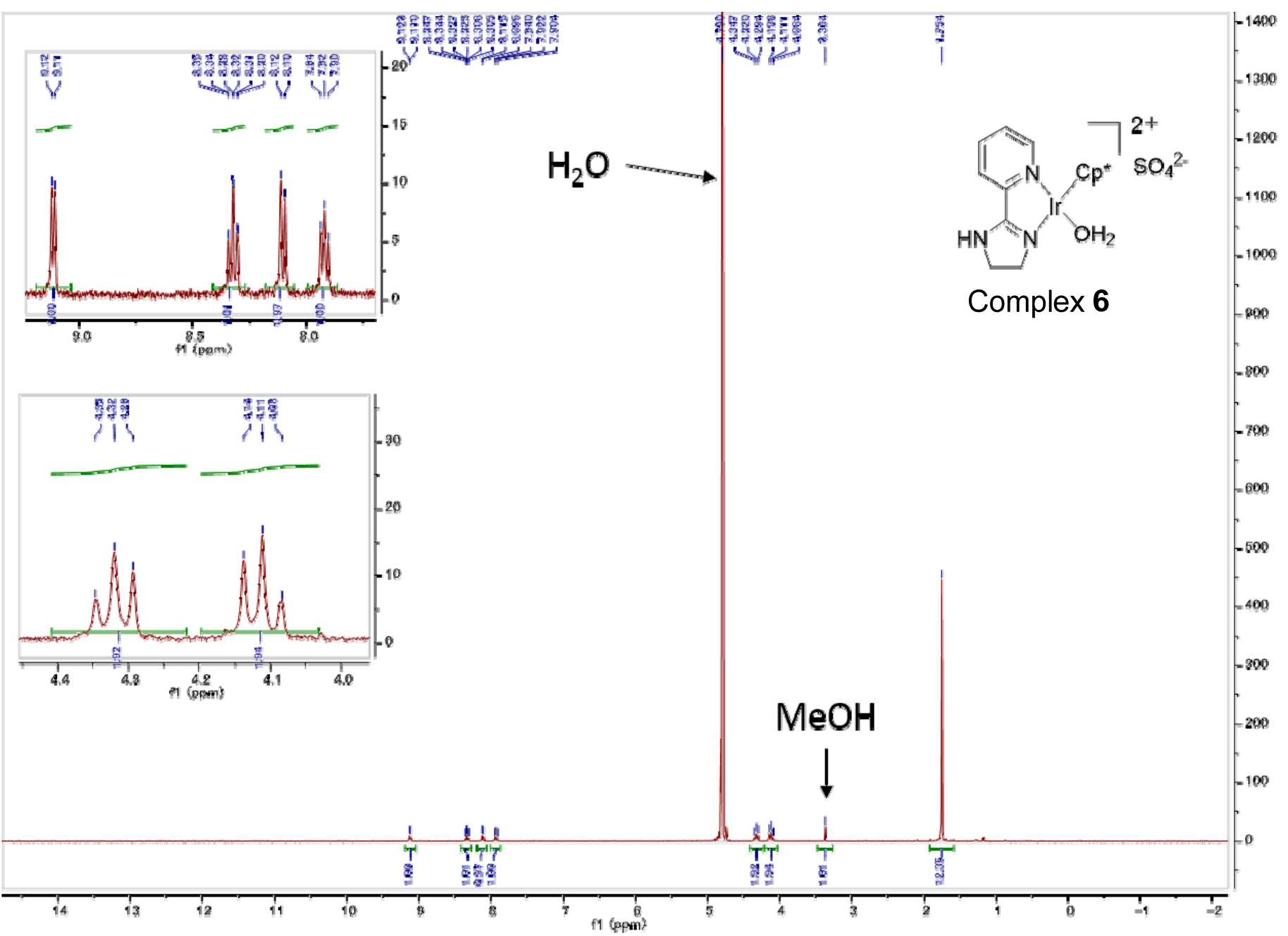




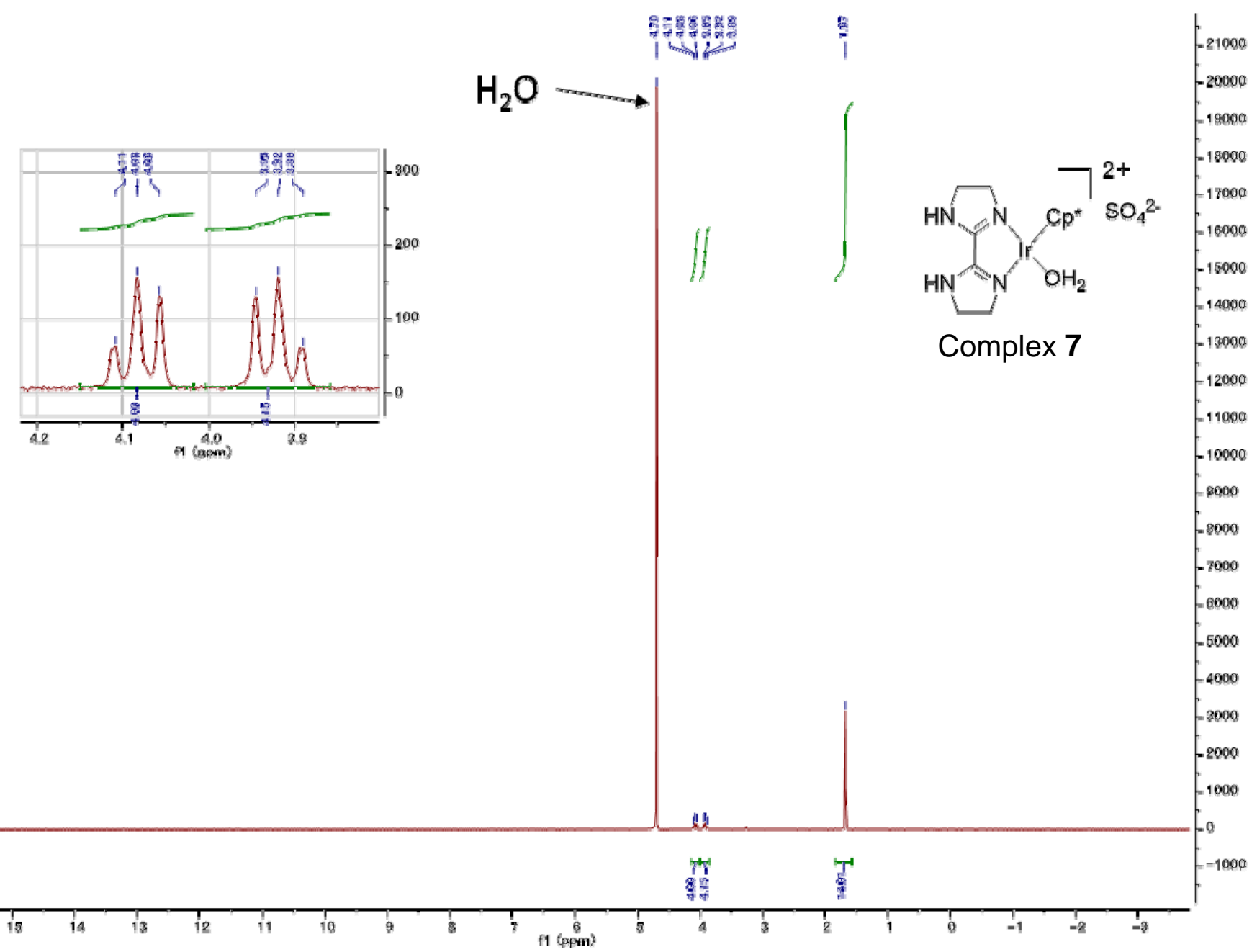




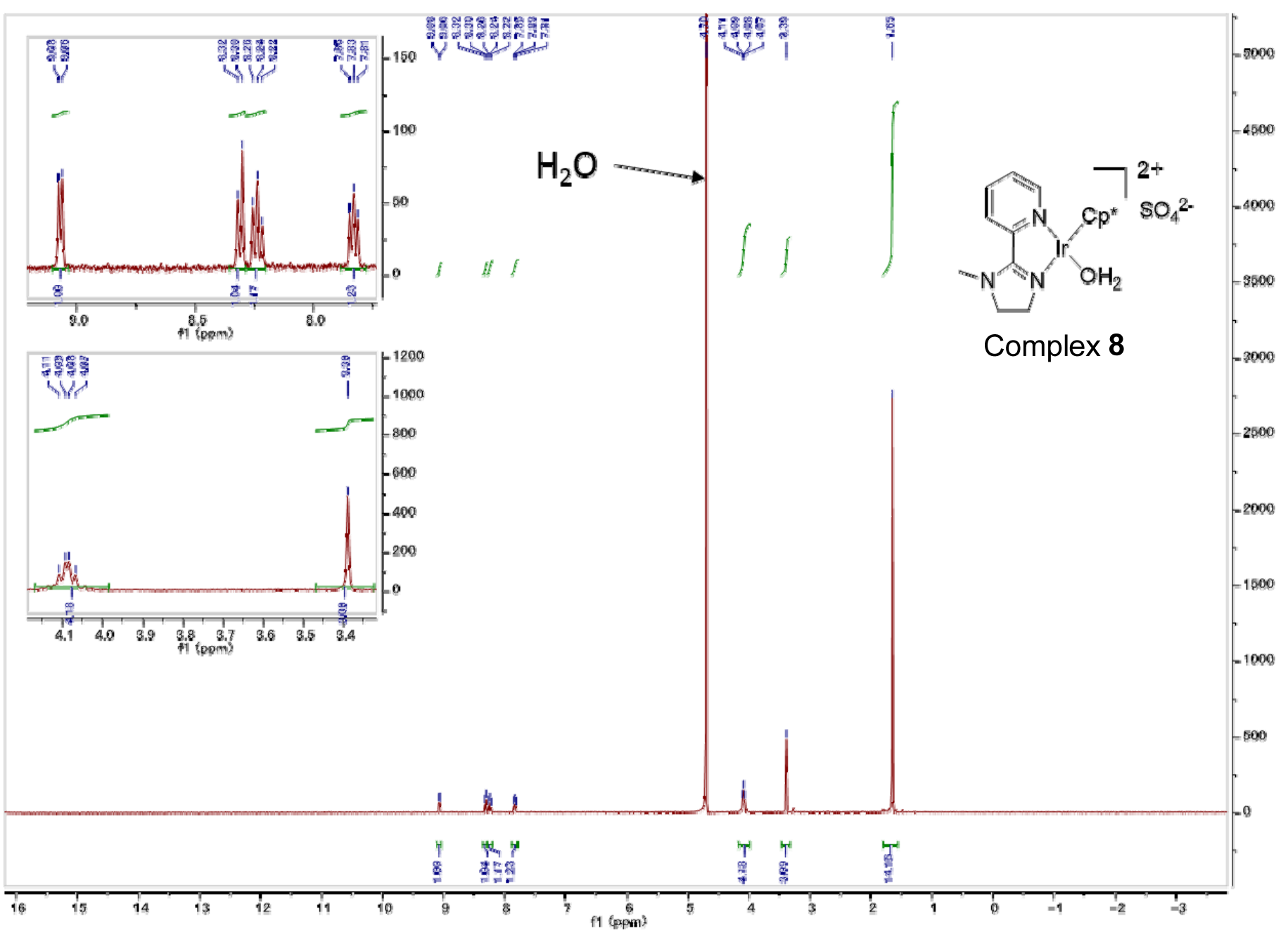

